\title{
Globalización y Relaciones Laborales
}

\section{Ermida Uriarte, Oscar*}

\section{Resumen}

El presente ensayo discute la globalización y su contexto, con énfasis en el desinterés por el mercado interno, la limitación del poder estatal para gobernar las variables económicas y el predominio de ideologías que no privilegian al factor trabajo, los cuales constituyen dramas para los trabajadores. En este marco, se analiza el cuestionamiento que sufre el sistema tradicional de relaciones laborales, con el objetivo de abaratar el costo del trabajo y sobre esta base garantizar la competitividad. Para ello la práctica gerencial va delineando un modelo posmoderno de relaciones laborales cuyas características serían: descentramiento del trabajo, segmentación de la mano de obra, inestabilidad en el empleo, individualización de las relaciones de trabajo y como resultado de todo lo anterior, abaratamiento del costo del trabajo. El análisis de las implicaciones de los rasgos del paradigma posmoderno obligan a iniciar la discusión de un eventual modelo alternativo de relaciones de trabajo, que considere el carácter internacional de las mismas y por lo tanto de sus actores, así como la necesidad de profundizar la regulación internacional.

Palabras clave: Globalización, integración regional, relaciones laborales, trabajo, empleo, flexibilización.

Profesor de Derecho del Trabajo en la Facultad de Derecho de la Universidad de la República (Uruguay). Miembro de número de la Academia lberoamericana de Derecho del Trabajo. Fun cionario del CINTERFOR/OIT. 


\title{
Globalization and Labor Relations
}

\begin{abstract}
This essay discusses globalization and its context, with emphasis on its lack of interest as to the internal market, the limited power of the state to control economic variables, and the predominance of ideologies that do not favor the work force, and which constitute problems for workers. In this framework, we analyze the questioning of traditional labor relations system based on the objective of lowering labor costs to guarantee competitiveness. In order to do this, management develops post-modern models of labor relations the characteristics of which are: decentralization of work, segmentation of the work force, labor instability, individualization of labor relations, and as a result of all this, cheaper labor costs. The anaiysis of the implications of these characteristics of the post-modern paradigm force us to initiate a discussion of a probable alternative model of labor relations that considers the international character of the same, and the actors in the process, as well as the need to develop more deeply the area of international regulation.
\end{abstract}

Key words: Globalization, regional integration, labor relations, work, employment, "flexibilization".

\section{La globalización y su contexto}

Más allá de sus diversos aspectos y manifestaciones -cuya variedad la convierten en un fenómeno complejo, multíacético y dinámico-, la globalización puede ser reducida, en su más íntima esencia, a la expansión y profundización de la economia capitalista y de sus postulados teóricos, tales como libre competencia, mercado, libre cambio, incremento de exportaciones, etc. La caducidad del mundo bipolar que habia caracterizado a la mayor parte del siglo $X X$, aceleró e intensificó aquella expansión, a la vez que entronizó, sobre todo en el terreno económico, el pensamiento único o hegemónico: el neoconservadurismo, neoclasicismo o neotiberalismo, originario de los años ' 30 y ' 40 , ahora es desempolvado e instalado como verdad reve. lada, probablemente porque ya no parece (tan) necesario mitigar los aspectos más inequitativos del capitalismo.

Este proceso globalizador entraña, por lo menos, tres dramas para los trabajadores y para todos los que se preocupan por los problemas sociales: a) el relativo desinterés por el mercado interno; b) la limitación del poder estatal para gobernar las variables económicas; y c) el predominio de ideologías que no privilegian al factor trabajo. Analicemos brevemente estos "tres dramas".

En el sistema económico predominante antes de la globalización, el de la "sustitución de importaciones", más allá de las sinceras y altruistas preocupaciones sociales de gobiernos y empleadores por las condiciones de vida y trabajo de la población en general y de los trabajadores en particular, había un interés egoísta de ambos en mantener cierto poder adquisitivo de la población, ya que se producia para esos consumidores. Los traba- 
jadores y la población nacional eran "el mercado" de la industria nacional que procuraba -con la ayuda del gobierno-, sustituir importaciones. El poder sindical y las concepciones ideológicas y políticas predominantes reforzaban este pacto tácito, esta alianza circunstancial, relativa y crítica, entre capital nacional (o instalado en el país), trabajadores y Estado. En cambio, en el nuevo sistema de economía globalizada, de libre comercio internacional y de "sustitución por importaciones", ni el empresario capitalista, ni el gobierno que aplica políticas económicas neoclásicas tienen ya interés egoista en mantener el poder adquisitivo de su población, ya que ella es cada vez menos sumercado, dado que éste se encuentra cada vez más, fuera de fronteras.

Paralelamente, la globalización de la economía aleja paulatinamente los resortes intimos del poder, del alcance del gobiemo nacional y de toda otra estructura limitada por las fronteras nacionales. Ser local en un mundo globalizado es una minusvalidez. La movilidad del capital y de las comunicaciones ha producido una compresión del espacio-tiempo en tal medida, que bien podria hablarse de un fin de la geografla con bastante más propiedad y menos frivolidad que del pretendido fin de la historia. Hoy, en el mundo globalizado, las elites son móviles y de comunicación instantánea, 0 no son elites. $Y$ todo esto ha dado una ventaja tremenda al capital sobre el Estado y sobre el trabajo, ya que la movilidad casi instantánea de que hoy disfruta el capital, contrasta con la necesaria localización del Estado nacional y la cultural localización del factor trabajo que por razones humanas, familiares y económicas, es infinitamente más sedentario y arraigado que el capital. Así, la globalización contribuye a que el poder político sea cada vez menos autónomo y que, en general, los contrapesos nacionales pierdan parte de su eficacia; entre ellos, el Derecho del trabajo y la acción sindical.

Naturalmente, este proceso va acompañado de una ideologia legitimadora, que tiende a privilegiar al capital sobre el trabajo.
La competitividad de la empresa en el mercado global se convierte en el bien supremo al que se subordinan los demás. Los intereses individuales son más valorizados que antes, mientras que los colectivos tienden a perder prestigio. La solidaridad pasa de moda y el egoísmo tiende a ser considerado como un motor del progreso. La eficacia comercial justifica los medios. El Estado de bienestar, que habia cumplido una función de contención del comunismo y de promoción del consumo nacional, ya no es considerado como necesario. El Derecho laboral y la acción sindical pueden ahora, ser vistos como obstáculos al desarrollo de la libre empresa. Por lo demás, en la medida en que las nuevas tecnologias siguen sustituyendo mano de obra, los trabajadores van siendo menos necesarios y disminuye su peso en la economia y la política. De todos modos, llama la atención la entronización del empresario, precisamente en el momento en que fracasa en su función social: la de generar empleo. Recuérdese que la denominación de empleador, que identifica a la parte empresaria en las re. laciones de trabajo, quiere decir el que da empleo, el que emplea a otro, o sea, dador de trabajo.

\section{El cuestionamiento del sistema tradicional de relaciones laborales}

En el marco que se acaba de describir. el sistema tradicional de relaciones laborales viene sufriendo cuestionamientos y cambios de diversos origenes. No es lácil distinguir cuáles de ellos provienen directamente de la globalización y cuáles de otras causas más o menos autónomas pero concurrentes.

Aquel sistema tradicional tiene por eje una relación de trabajo que vincula al trabajador con un mismo empleador por tiempo indeterminado. En efecto, a la relación de trabajo clásica se ingresa (¿se ingresaba?) con vocación de continuidad. Asimismo, ese ingreso se producía para desarrollar una tarea 
determinada, claramente definida y a cambio de una remuneración preponderantemente fija. Esa relación es regulada por el Estado y por el sindicato, con la finalidad de proteger a la parte más débil: el trabajador. Por eso, la red normativa de este sistema tradicional de relaciones industriales es un Derecho laboral unilateralmente protector, en América Latina predominantemente heterónomo, es decir, de fuente estatal, y en otros países predominantemente autónomo, con predominio de los convenios colectivos, pero siempre con un componente estatal y otro colectivo y con una tinalidad de tutela.

Cabe agregar que este sistema tradicional de relaciones laborales se da en una sociedad en la cual el trabajo ocupa un lugar central. En efecto, el trabajo es, por una parte y en primer término, el medio de vida del trabajador y de su familia; de ahí la importancia del salario, de su estabilidad y suficiencia. Pero por otra parte, el trabajo es, en esa sociedad, el principal medio de identificación e inclusión social del individuo. Tan es asi, que una de las primeras preguntas que se hacen sobre una persona que no se conoce, además del nombre y eventualmente la edad aproximada, es "¿y qué hace?", "¿a qué se dedica?", o"¿en qué trabaja?". Identificación social, pues. Pero también inclusión, porque del salario y del trabajo depende toda la red de protección social que hace del trabajador un ciudadano en el sentido político y soclal del término: miembro de la so. ciedad y de la nación (jubilaciones, pensiones, seguros sociales por enfermedad o accidente, etc.). En idéntico sentido operan los servicios sociales que algunas empresas y sindicatos ofrecen a sus trabajadores y afiliados.

La globalización coloca en primer plano la preocupación por la competitividad internacional de la empresa y ésta pone en cuestión el costo del sistema tradicional. Le sirven para ello, como anillo al dedo, los postulados neoliberales en materia laboral:

1. no intervención del Estado en las relaciones individuales, para que cada trabajador negocie el precio de su trabajo libremente con el empleador, sin sujeción a topes mínimos; $y$

2. intervención del Estado en las relaciones colectivas a efectos de limitar, restringir y si fuera politicamente posible, eliminar la acción sindical, la negociación colectiva y la huelga, fenómenos éstos que, en la doctrina neoliberal no son vistos como derechos fundamentales ni como instrumentos de equidad, sino como prácticas monopólicas de los vendedores de fuerza de trabajo, que obstaculizan el libre juego de la oferta y la demanda de trabajo.

Este programa de destrucción metódica de lo colectivo apunta al objetivo de provocar la total individualización de las relaciones de trabajo. Llevado a su máxima expresión, el proyecto neoliberal crearía, entre trabajador y empleador, una relación individual y desregulada, sin sindicato, sin negociación colectiva, sin derecho de huelga, sin legislación especial, $\sin$ Inspección del Trabajo y sin Justicia especializada.

¿Por qué? ¿Para qué? Teóricamente, para abaratar el costo del trabajo y así contribuir a incrementar la competitividad de la empresa y aumentar el lucro empresario, lo que provocaría inversiones que generarían nuevos empleos y asi, por "chorreo" o "goteo", la concentración del ingreso terminaría beneficiando a todos.

Está claro que este programa, si se aplicara en plenitud -lo que, como sucede con todo proyecto teórico, nunca sucedió en la realidad-, no solo provocaría efectos sobre las relaciones laborales, sino que produciría su desaparición. En efecto, llevaria a la abolición del sistema de relaciones de trabajo y a su sustitución por múltiples relaciones privadas de cada persona que trabaja para otra con aquella que compra su trabajo, en un mercado libre. No habria Derecho del trabajo, sino Derecho civil o comercial (como en el siglo XIX), ni habrian relaciones laborales, sino relaciones civiles o comerciales. 
$Y$ si bien, como se viene de decir, este proyecto no ha sido aplicado en su totalidad, ha coexistido con otras tendencias que potencian sus efectos debilitadores del sistema tradicional de relaciones laborales: en especial, la innovación tecnológica sustitutiva de mano de obra y generadora de flexibilidad en la organización del trabajo, todo lo cual ha instalado un sistema económico que destruye empleo y segmenta el empleo existente.

\section{El paradigma de las relaciones laborales posmodernas}

De esta forma, el modelo neoliberal acicateado por la globalización y sumado a los efectos del cambio tecnológico, va delineando una suerte de paradigma de relaciones laborales posmodernas.

Como va dicho, el paradigma teórico puro, sería la disolución de las relaciones laborales en relaciones individuales, civiles o comerciales. Pero como esto no ha sucedido en la práctica -de hecho, siguen existiendo sindicatos, negociaciones colectivas y huelgas, Códigos del trabajo, Administración pública laboral y Justicia del trabajo., la resultante, por el momento, va quedando "a mitad de camino".

Algunas de las características de estas relaciones laborales posmodernas serían las siguientes: descentramiento del trabajo, segmentación de la mano de obra, inestabilidad en el empleo, individualización de las relacio. nes de trabajo y abaratamiento del costo del trabajo.

En primer lugar, el "descentramiento" del trabajo. Con la priorización del capital sobre el trabajo y la sustitución creciente de mano de obra por tecnología, cada vez es posible producir más y mejor con menos número de trabajadores. El trabajo es hoy, menos necesario. Las consecuencias obvias y naturales son el aumento del desempleo y la exclusión social. Porque la economia actual destruye puestos de trabajo, pero la sociedad continúa basando la ciudadanía y la inclusión sociales en el trabajo.

En segundo término, la segmentación de la mano de obra. La flexibilidad productiva alienta la descentralización de la organización del trabajo, la cual es facilitada por la desregulación o flexibilización del Derecho laboral. Crecen la informalidad y la tercerización, y las empresas tienden a organizarse sobre la base de dos grupos bien diferenciados de trabajado. res: a) un núcleo de trabajadores estables, protegidos, con buenas remuneraciones y calificaciones, y b) una "periferia" inestable, precaria, rotativa, tercerizada o informal.

En tercer lugar, la inestabilidad en el empleo, no solo -y muy notoriamente- en esa periferia precaria y rotativa, sino incluso en el conjunto, habida cuenta de la flexibilización o desregulación de la contratación laboral y del despido, así como de la mayor sensibilidad de la empresa a los avatares de la competencia internacional y de variables externas, como los flujos de capitales especulativos.

En cuarto término, la individualización de las relaciones laborales, en diversas dimensiones. Por un lado, una mayor individualización se produce como resultado de la desregulación o flexibilización del Derecho del trabajo, que amplía el ámbito de la autonomía de la voluntad del empleador y llega a tolerar que "escapen" de la legislación laboral hacia el Derecho privado, relaciones que antes estaban indiscutiblemente reguladas por aquélla. Por otro lado, la individualización se produce, asimismo, por cierto retroceso de las relaciones colectivas de trabajo, sea cediendo espacio a relaciones propiamente individuales, sea -en otros casos- descentralizando relaciones co lectivas típicas, como tiende a suceder con la negociación colectiva, al influjo del mayor poder del empleador en el actual contexto. En definitiva, la descentralización de la negociación colectiva forma parte de un continuo que apunta a la individuallzación de las relaciones de trabajo. No se trata aqui de desconocer el principio de que debe ser posible negociar colecti- 
vamente a todos los niveles, ni tampoco de negar que la negociación colectiva descentralizada puede tener ventajas para tratar determinados asuntos específicos de cada empresa y que no son comunes a la rama de actividad, sino solamente de llamar la atención respecto de que, sin perjuicio de ello, existe un iter que va de la negociación colectiva centralizada a la negociación colectiva descentralizada y de ésta a la relación individual.

En quinto lugar, y como resultante de todo lo anterior, se produce el abaratamiento del costo del trabajo. Si hay menos empleo y más desempleados, si el empleo tiende a precarizarse salvo para un núcleo relativamente reducido, si se abaten las medidas legislativas de protección y ellas no son compensadas por la acción de un sindicato debilitado, la consecuencia es una reducción del salario real, una concentración de la riqueza y un descenso de la participación del salario en la renta nacional. Esa reducción salarial se refuerza con la introducción de modalida. des salariales más lígadas al rendimiento, con la flexibilización de los horarios en función de las necesidades productivas, y con la acentuación de la movilidad funcional.

Poco más o menos, este es el modelo de relaciones laborales que se va delineando. Quedan, sin embargo, muchas dudas. Una de ellas es la de si estamos ante un modelo de relativa estabilidad histórica o solo ante una etapa de transición hacia la disolución de las relaciones laborales, cuestión vinculada, además, con la del "fin del trabajo". Otra interrogante acuciante, es la de si es éste un modelo viable y funcional, y en caso de que no lo fuera, cuál podria ser un modelo alternativo.

\section{4. ¿Un modelo alternativo de relaciones laborales?}

No se trata aqui de predecir el futuro. La elucubración sobre un eventual modelo alternativo de relaciones laborales se justifica ante lo que parecen ser disfuncionalidades insalva- bles del paradigma posmoderno. En efecto, la proyección de ese modelo al futuro hace dudar sobre su viabilidad.

La primera pregunta sin respuesta es: ¿Cuál es el umbral de exclusión que admite la sociedad, sin provocar la eclosión de una nueva cuestión social y el quiebre del sistema democrático? ¿Cuál es la estabilidad, a mediano y largo plazo, de un modelo que excluye a un número superior de los que incluye?

La segunda cuestión es que la desregulación laboral no se ha mostrado eficaz para la generación de empleo ni para detener el creciente desempleo, mientras que en cambio, si ha demostrado aumentar la precariedad del empleo existente. No se crea más empleo -porque la causa de la desocupación no está en las normas laborales-, y se degrada la calidad del empleo que resta.

Tampoco parece evidente que el abatimiento del costo del trabajo determine, por sí solo, una mayor competitividad de la empresa. Entre otras razones porque la competitividad de la empresa no depende solamente de la competitividad de la mano de obra máxime cuando el costo del trabajo supone por regla general -y especialmente en Latinoamérica-, un porcentaje muy bajo del costo total de producción y del precio de venta del producto o servicio.

Por lo demás, la precarización y rotatividad de la mano de obra estaría en abierta contradicción con dos axiomas de la moderna administración de personal. Una empresa competitiva requiere personal calificado e involucrado en los objetivos de la firma. $Y$ no es razonable pretender que un empleador invierta en la capacitación de un trabajador que sabe que en poco tiempo estará fuera de la empresa, ni es tampoco razonable pretender que ese trabajador se involucre en los objetivos de una empresa que sabe que en breve lapso prescindirá de sus servicios.

Asi, parece llegado el momento de comenzar a pensar que un modelo viable de relaciones laborales debe basarse en la promo- 
ción de la continuidad y no de la rotatividad y precariedad de la plantilla.

Esta continuidad o estabilidad permitirá -y debería estar necesariamente acompañada de- la formación profesional inicial y continua, siendo esta última la que, basada en la primera, puede adaptar y desarrollar permanentemente las competencias del trabajador, lo que redunda en beneficio propio, porque le permite mantener su empleo aunque éste sea cambiante en su contenido, y en beneficio de la empresa y de la economia nacional en su conjunto, que cuentan con esa ventaja comparativa insustituible que es el personal altamente calificado.

La permanencia y la calificación del trabajador permitirán, ellas sí, su involucramiento con los objetivos de la empresa $y$, más importante aún, permitirán y favorecerán su polifuncionalidad. Esta, a la vez, permitirá la permanencia y no la sustitución del trabajador, ante los cambios tecnológicos u organizativos.

Ello supone admitir, también, un determinado grado de flexibilidad interna contrapartida de la estabilidad, permanencia o continuidad-, que permita al empleador aprovechar la polifuncionalidad del trabajador y mantenerlo en la planilla.

Esta flexibilidad interna podría incluir también, la flexibilidad de la jornada de tra* bajo, que permita al empleador adaptar el ritmo de trabajo a las necesidades de producción, pero también como contrapartida de la inexorable reducción del tiempo de trabajo, habida cuenta de la necesidad de proceder a algún grado de reparto del trabajo disponible, y en ese aspecto, como medida de inclusión social o, por lo menos, de freno o mitigación de la exclusión (ello, sin periuicio de la constatación de que la reducción del tiempo total de trabajo es una resultante mecánica de la sustitución de mano de obra por tecnología).

Un modelo de este tenor no podría prescindir del sindicato y de la negociación colectiva. En primer lugar -y ello bastaría-porque se trata de derechos humanos básicos. Pero además, porque son importantes instrumentos de adaptabilidad de los derechos y relaciones laborales a las necesidades de la empresa y del trabajador. El sistema neoliberal y posmodemo olvidó el papel que el sindicato y la negociación colectiva juegan en el gobierno del sistema de relaciones laborales. Habria que rescatar esta función.

Pero hasta aqui, este esquema se ha movido en el marco nacional: y si bien la globalización no es la única causante del actual estado de cosas en el mundo del trabajo, lo cierto es que si constituye uno de los principales factores concurrentes. La internacionalización de la economía, la extranacionalización de las principales fuentes de poder, la globalización o regionalización de la producción, van generando dos procesos que es necesario destacar: a) el surgimiento de un sistema internacional de relaciones laborales; y b) la demanda de una "re-regulación internacional" de las relaciones de trabajo.

\section{Las relaciones laborales internacionales}

Ya se dijo que la globalización de la producción, del comercio y de las finanzas tiende a ubicar los centros de gravedad de los procesos de toma de decisiones más allá del alcance territorial del Estado-nación y que va acompañada de la comprensión del espacio-tiempo, a tal punto que quienes deciden e influyen deben estar dotados de movilidad y posibilidad de comunicación instantánea (supra, párrafo 1).

Al mismo tiempo, una de las respuestas al proceso globalizador, ha sido, en algunas partes, la regionalización económica, esto es, la construcción de bloques de integración económica regional que tienden a ampliar el mercado interno y a construir una unidad mayor que permita a sus miembros competir mejor en el comercio intemacional con el resto del mundo.

Ambos procesos la globalización y la integración regional-, tienden a exigir el redi- 
mensionamiento del sistema de relaciones laborales. En efecto, un sistema nacional de relaciones laborales -lo mismo que el Estado nacional-se va revelando cada vez más impotente para incidir en un terreno que está más allá de sus límites físicos.

La globalización y la regionalización suponen la internacionalización (ya sea a nivel global o regional) del contexto de las relaciones laborales. Y la internacionalización del contexto exige la internacionalización de los actores y de sus relaciones. En otras palabras, la globalización y la regionalización exigen y/o provocan la internacionalización de las estructuras sindicales y de la acción sindical, en especial, de la negociación colectiva y de la huelga.

Dicho en otras palabras: la globalización y la integración regional instalan un nuevo escenario que ya no es (solamente) el nacional; a éste se superpone ahora, otro multinaclonal (sea regional o planetario). $Y$ en ese nuevo escenario, mayor y diferente, ya no pueden actuar solo los viejos actores nacionales, pensados para aquél. Es necesario reestructurar a los actores o crear nuevos actores apropiados para la dimensión del nuevo escenario y de las relaciones -ya no exclusivamente nacionales- que inevitablemente surgirán en el nuevo contexto.

El redimensionamiento del contexto-escenario, exige el redimensionamiento de los actores y de las relaciones de negociación y conflicto entre ellos.

La internacionalización de las estructuras de los actores no se ha dado con claridad en el marco de la mundialización, aunque desde antaño existen estructuras internacionales tanto del lado sindical (como lo son las confederaciones internacionales CIOSL, CMT y FSM), como del lado patronal (la OIE). Pero ella se ha producido con más notoriedad en dos espacios de integración económica regional: la Unión Europea y el Mercosur.

En la Unión Europea funcionan, desde hace tiempo, la CES (Confederación Europea de Sindicatos) y su contraparte patronal, la UNICE.

En el Mercosur, quienes primero percibieron la necesidad de crear una estructura regional, fueron los trabajadores. Paralelamente con la negociación y adopción del Tratado de Asunción (acto fundacional del Mercosur, firmado el 26 de marzo de 1991), las organizaciones sindicales de Argentina, Brasil, Paraguay y Uruguay echaron mano a una institución preexistente: la Coordinadora de Centrales Sindicales del Cono Sur, que habia sido creada en 1986 para apoyar el proceso de democratización latinoamericano, aún pendiente, a la sazón, en Bolivia y Chile.

A comienzos de los ' 90 , esta Coordinadora de Centrales Sindicales del Cono Sur había cumplido su función y fue entonces revitalizada para operar como estructura sindical del y en el Mercosur. Para ello se creó en su interior la Comisión Sindical del Mercosur que, desde 1991 hasta hoy, ha tenido una permanente, intensa y relativamente fructífera participación en toda la construcción del espacio social del Mercosur. Es probable que la Coordinadora de Centrales Sindicales del Cono Sur -actuando a través de su Comisión Sindical del Mercosur-, haya sido el principal motor del reconocimiento de la existencia de una dimensión social del Mercosur, primero, y de la paulatina construcción de un espacio social del Mercosur, después.

Los empleadores del Mercosur reaccionaron más tardiamente en este aspecto. Recièn en 1994 se constituyó el Consejo Industrial del Mercosur y en 1995 el Consejo de Cámaras de Comercio del Mercosur; en 1997, en una sesión del Foro Consultivo Económico-Social del Mercosur, un representante empresarial anunció la constitución de una Confederación Agrícola del Mercosur. Pero en general, la presencia y acción de estas instituciones en tanto tales, ha sido mucho menor a la de la Coordinadora sindical; la participación de los empleadores ha sido permanente, pero no la intervención institucional de las mencionadas estructuras regionales. 
El diálogo social Internacional, incluida la negociación colectiva multinacional, también ha tenido un cierto grado de reconocimiento y consagración práctica en esos dos bloques de integración regional, a despe. cho de su escasa o nula plasmación a una escala propiamente global.

Enla Unión Europea, la CES y la UNICE han llevado a cabo un importante proceso de diálogo social internacional europeo que, a pesar de marchas y contramarchas y de valoraciones diferentes de parte de diversos observadores, en todo caso ha dado lugar, por una parte, al establecimiento de un diálogo social regional, y por otra, a una serie de acuerdos, opiniones conjuntas o dictámenes comunes sobre muy diversos temas laborales. Desde el punto de vista formal, el ordenamiento jurídico europeo reconoce, actualmente, a los convenios colectivos europeos como fuente de Derecho regional y más aún, abre un espacio especial para el ejercicio de la autonomia colectiva europea, en el proceso de adopción de Directivas. Paralelamente, existen varios casos de convenciones colectivas de empresas multinacionales europeas, que cubren a los diversos establecimientos que esas firmas controlan en la región.

En el Mercosur, mientras tanto, la reciente Declaración Sociolaboral reconoce entre los derechos colectivos, el del diálogo social "nacional y regionar", que los Estados Partes se comprometen a fomentar. Asimismo, más reclentemente aún, se celebró el primer convenio colectivo regional o multinacional del que tengamos noticia en América Latina. Se trata del contrato colectivo pactado el 16 de abril de 1999 entre la empresa Volkswagen de Argentina y Brasil, por una parte, y los sindicatos metalúrgicos de la CUT de Brasil y el sindicato de mecánicos de Argentína.

Concebido como un convenio colectivo "mercosureño", este acuerdo se fundamenta expresamente, según consta en uno de sus "considerandos" en "la necesidad de extender los acuerdos de las relaciones entre capital y trabajo al ámbito del Mercosur". En ese marco, establece el intercambio de información; la realización de una reunión anual conjunta entre las empresas y los sindicatos y las comisiones internas de fábrica; el compromiso de prevención de conflictos a través del diálogo permanente y de solución de las divergencias a través de la negociación, en la medida de lo posible; el reconocimiento, por parte de las empresas, de la representatividad de los sindicatos celebrantes y las comisiones internas, como interlocutores para el tratamiento de los asuntos laborales y del derecho de los trabajadores a organizarse sindicalmente y a constituir las susodichas comisiones internas de fábrica; finalmente, este convenio contiene interesantes disposiciones en materia de formación profesional, previendo la "homogeneización" de los programas de capacitación, la cooperación de los sindicatos y comisiones internas en la elaboración de los programas y el reconocimiento automático de los cursos realizados en cualquiera de los establecimientos de la firma en el Mercosur.

La participación de los trabajadores en la empresa ha tenido una muy importante difusión europea, contrastante con su nulo desarrollo en el Mercosur, abstracción hecha de las previsiones precursoras contenidas en el contrato colectivo de Volkswagen recién referido.

La práctica desarrollada en Europa de instalar mecanismos multinacionales de información y consulta tuvo su consagración formal y se espera que un nuevo impulso, a través de la adopción por el Consejo de Europa, el 22 de septiembre de 1994, de la Directiva 94/95/CE, sobre la constitución de un procedimiento de información y consulta a los trabajadores en las empresas y grupos de empresas de dimensión comunitaria.

El conflicto internacional se ha verificado en diversas circunstancias, tanto en Europa como en América del Norte, en este caso, involucrando a trabajadores y empresas de Canadá y USA. En el Mercosur solo se han da do algunas movilizaciones regionales que, por el momento, podrian calificarse de experimen- 
tales (paro de una hora de los trabajadores de la energía eléctrica del Mercosur, el 12 de noviembre de 1996, movilización conjunta el 17 de diciembre de 1996 en ocasión de una reunión de presidentes de los países del Mercosur en Fortaleza, Brasil, y celebración conjunta del $1^{\circ}$ de mayo de 1999 en la ciudad uruguaya de Fivera, situada en la frontera con Brasil).

Finalmente, en cuanto a la participación instítucional en los procesos de globalización y regionalización, debe señalarse que, a nivel mundial, la Organización Internacional del Trabajo ha ofrecido, a lo largo de este siglo, la mejor y mayor experiencia, a partir de su propia estructura tripartita. Es, inclusive, el único ejemplo de participación global, universal o planetaria.

En el campo regional, el Comité Económico y social de la Unión Europea y el Comité de las regiones son los órganos destinados a hacer posible tal participación. En el Mercosur, el Foro Consultivo Económico-Social es el único órgano permanente, previsto en los tratados fundacionales, destinado a vehiculizar la representación y participación orgánica de los actores sociales. Sin embargo, ha tenido gran importancia, también, el Subgrupo de Trabajo No. 10. comisión de funcionamiento tripartito con competencia en asuntos laborales; de su seno surgieron muy importantes iniciativas, como la propuesta de ratificación de un elenco común de convenios internacionales del trabajo por los cuatro países miembros del Mercosur, el proyecto de Convenio Multilateral de Seguridad Social del Mercosur, ya aprobado por los órganos regionales y a la espera de su ratificación por los congresos nacionales y la adopción de la Declaración Sociolaboral del Mercosur.

Cabe consignar que, en materia de participación institucional, también el Pacto Andino ha dado lugar a diferentes órganos e instancias: el Consejo Asesor Económico y Social (previsto en el Acuerdo de Cartagena, tratado fundacional), el Consejo Consultivo empresarial (creado por la Decisión 175 de 1983) y el Consejo Consultivo laboral (creado por la Decisión 176, del mismo año).

\section{La "re-regulación internacional"}

Si la globalización está generando una cierta inanidad de los sistemas nacionales de relaciones laborales y en especial de su red normativa, si las legislaciones nacionales se van mostrando menos eficaces para regular fenómenos que se desarrollan o tienen sus causas a otro nivel, si ello -junto a otros factores concurrentes- tiende a generar situaciones indeseables o disfuncionales de exclusión y precarización, y si además hay una tendencia al surgimiento o desarrollo de relaciones laborales supranacionales, parece evidente la procedencia de la propuesta de algunos autores en el sentido de ir a una re-regulación internacional de las relaciones de trabajo.

Los convenios internacionales del trabajo, los grandes Pactos y Declaraciones de derechos humanos, las Cartas sociales, las cláusulas sociales y algunos sustitutos unilaterales de estas últimas, son algunas de las formas adoptadas, utilizables o propuestas, por el momento, para una tal "re-regulación interna" cional", tendiente a ubicar la red normativa al nivel de desarrollo de los fenómenos que debe regular. Un sistema internacional de relaciones laborales debe desarrollar una red normativa internacional.

6.1 Los convenios internacionales del trabajo emanados de la OIT son el primero y el más desarrollado de los intentos de generar una red normativa universal. Más aún, es, por ahora, el único que ha alcanzado una dimensión global o planetaria. Apunta a establecer normas mínimas para las condiclones de trabajo y relaciones laborales, en base a cuatro fundamentos: la justicia social, la constatación de que la paz es imposible sin equidad, el principio de que el trabajo no puede ser tratado como una mercancía, y la preocupación por el "dumping social". Respecto a este último aspecto, tan reactualizado a causa de la globalización, cabe recordar que el Preámbulo de la Constitución de la 
OIT establece, ya desde 1919, que "si cualquier nación no adoptase un régimen de trabajo realmente humano, esta omisión constituiria un obstáculo a los esfuerzos de otras naciones que desearen mejorar la suerte de los trabajadores en sus propios paises".

Cuando mucho después, ya en los ' 90 , la globalización replantea el problema del vínculo entre el desarrollo del comercio internacional y el cumplimiento de ciertos mínimos laborales, la OIT lanza una campaña de ratificación universal de un reducido número de convenios considerados "fundamentales", sobre libertad sindical y negociación colectiva ( 87 y 98 ), no discriminación (100 y 111), trabajo forzoso (29 y 105), y trabajo intantil (138, al cual se suma, en 1999, el nuevo convenio 182).

Paralelamente, en 1998, la Conferencia Internacional del Trabajo aprueba la Deciaración de Principios y Derechos fundamentales en el trabajo, según la cual, todo país, por el solo hecho de ser miembro de la OIT, se compromete a cumplir los principios contenidos en aquellos convenios, aún cuando no los haya ratificado.

Como se ve, desde cierto punto de vista, se trata de dar un salto cualitativo, apuntando a universalizar o "globalizar" los principios contenidos en determinado número de convenios, independizando su eficacia del acto de ratificación nacional. Desde otro punto de vista, más bien pesimista, se ha dicho que la OIT ha adoptado una opción minimalista, respondiendo a las demandas de desregulación y flexibilización, con una circunscripción de sus esfuerzos al cumplimiento de un elenco reducido de convenios, lo que tácitamente supondría una despreocupación por los demás. ¿Comienzo de un proceso de universalización de la red normativa aún a despecho de cualquier ratificación nacional, o desregulación encubierta? Solo el transcurso del tiempo podrá dar una respuesta cierta.

6.2 Los grandes pactos y declaraciones de Derechos Humanos, en particular los emanados de la ONU, tienen también vocación universal. Tal es el caso de la Declaración
Universal de los Derechos Humanos de 1948, el Pacto Internacional de Derechos Civiles y Politicos de 1966 y el Pacto Internacional de Derechos Económicos, Sociales y Culturales del mismo año.

En el caso de los pactos sujetos a ratificación por los Estados, su eficacia juridica concreta en el plano nacional depende, para algunos, de la posición que se sostenga sobre la existencia de unidad o dualidad entre orden jurídico internacional y ordenes juridicos internos, así como de la jerarquía que aquél tenga en cada uno de estos. Sin embargo, también es posible sostener, y parece ser ésta una coriente destinada a la expansión -en consonancia, precisamente, con la mundialización-, que en tanto parte del "jus cogens", los derechos humanos reconocidos como tales por la comunidad internacional en esas grandes Declaraciones y Pactos integran el orden público internacional y por tanto, gozan de imperium más allá de todo acto de ratificación, convalidación o recepción nacional. Lo mismo puede decirse de las Declaraciones y Cartas americanas, aunque circunscriptas al plano hemisférico.

6.3 Normas laborales supranacionales (aunque restringidas al espacio regional), existen en la Unión Europea. Esta es la única entidad verdaderamente supranacional, que ha recibido transferencia de soberania de los Estados miembros, incluso en el ámbito laboral (por más que el Acuerdo Complementario Laboral del Tratado de Libre Comercio entre Canadá, México y USA prevé un Tribunal Arbitral que puede llegar a autorizar la aplica. ción de multas y suspensión de beneficios arancelarios al Estado infractor, en una clara vinculación del comercio internacional con los derechos de los trabajadores). Especialmente desde que el Tribunal de Justicia determinó la aplicación directa de las Directivas (originalmente dirigidas solo a los Estados con miras a la armonización de las legisiaciones naciona. les), cuando sus disposiciones fueran claras, precisas y autoejecutables, y desde que el Tratado de Amsterdam incorporó las Cartas (la Social Europea de 1961 y la Comunitaria de 
Derechos Fundamentales de los trabajadores de 1989) a los Tratados fundacionales.

6.4 Las Cartas Sociales, a despecho de la variedad que suelen ofrecer, pueden ser definidas tentativa y genéricamente como declaraciones solemnes en las cuales los Esta. dos proclaman clertos derechos y/o reconocen determinadas metas u objetivos laborales o sociales comunes. Apuntan a edificar el espacio social de un grupo de países, sobre la base de un zocalo mínimo común de derechos sociales, generalmente en un conjunto de naciones que consideran tener un perfil común (caso de la Carta Interamericana de Garantías Sociales de 1948) y especialmente en las que conforman un bloque de integración económica regional (caso de la Carta Social Europea de 1961, la Carta Comunitaria de Derechos Fundamentales del trabajador de 1989, y de la Declaración Sociolaboral del Mercosur de 1998).

Su objetivo principal es social: garantizar el reconocimiento de determinados principios y derechos considerados importantes en los paises signatarios.

Este objetivo puede limitarse a los países miembros o extenderse a las relaciones con terceros países. Asi: 1) al interior del bloque, la Carta Social se propone acordar aquellos derechos básicos que los miembros se comprometen a respetar por igual; y 2) al exterior del bloque, la Carta puede (no necesariamente) condicionar el comercio de los socios con terceros paises, al cumplimiento de los niveles sociales respetados por el bloque a su interior (lo que no sería incompatible con las normas de la OMC).

Pero en materia de Cartas Sociales lo esencial es el objetivo interno, no el externo. Así, por ejemplo, la Carta Social Europea de 1961 y la Carta Comunitaria de Derechos Fundamentales de los trabajadores de 1989 no tienen ninguna referencia al comercio exterior, ni al interior. Del mismo modo, la Declaración Sociolaboral del Mercosur de 1998, reconoce un elenco de derechos comunes a los países del bloque, independientemente del comercio in- trazona y sin que en ningún momento se plantee la exigencia de su cumplimiento a terceros paises que comercien con el Mercosur. Por su parte, algunos de los principios incluidos en el Anexo I del Acuerdo Laboral Complementario del TLC de Canadá, México y USA, pueden llegar a afectar el comercio entre esos paises, pero no se relacionan con el comercio de éstos con el resto del mundo.

Por otra parte, las sanciones por incumplimiento de una Carta Social -de existirpueden ser comerciales o no. Pueden ser políticas, morales y aún no existir; y si se establecen sanciones económicas, éstas pueden estar vinculadas al comercio internacional o no (solo cuando estas sanciones son económicas y se vinculan con el comercio internacional, la Carta Social puede funcionar como cláusula social).

En efecto, el contenido de una Carta Social puede ser puramente declarativo o programático y carecer de sanciones. Cuando sus cláusulas son vinculantes pueden (deberian) ir acompañadas de sanciones. Estas dependerán de que dichas cláusulas sean dirigidas a los gobiernos o que reconozcan derechos subjetivos de los ciudadanos. En todo caso, tales sanciones pueden consistir en observaciones o recomendaciones, multas, cancelación o supresión de beneficios arancelarios, o en sentencias declarativas $\circ$ constitutivas, si existe un tribunal o corte inter o supranacional.

En todo caso, también respecto de las Cartas Sociales puede plantearse la cuestión referida a la eficacia de las Declaraciones y Pactos sobre derechos humanos: ¿forman parte del "patrimonio jurídico de la humanidad", como dice uno de los Considerandos de la Declaración Sociolaboral del Mercosury por tanto pueden considerarse parte del "jus cogens ${ }^{n}$, o son meras declaraciones éticas de principios o buenos propósitos?

6.5 Las cláusulas sociales -a diferencia de las Cartas Sociales, las Declaraciones y Pactos sobre derechos humanos y las normas internacionales del trabajo-, solo tienen sentido dentro del comercio internacional o en 
relación con éste. Su propio nombre de "cláusula" (y no de "carta" o de "norma" o de "convenio"), señala que en lo esencial, en su forma original y conceptualmente pura, la cláusula social es una cláusula de un tratado, convenio o acuerdo comercial, en la cual las partes se comprometen a respetar y eventualmente a hacer respetar ciertos derechos sociales $y$, para el caso de violación de los mismos, pactan la caída de las ventajas que se han reconocido reciprocamente o las que hayan acordado a terceros países, o aún la simple rescisión por incumplimiento de todo el acuerdo.

Asi, el objeto de la cláusula social es el condicionamiento de las preferencias arance. larias $u$ otras ventajas comerciales ofrecidas a los socios (efectos al interior del acuerdo) o a los terceros (efectos al exterior del acuerdo), al cumplimiento de los derechos establecidos en dicha cláusula.

Claro que hay puntos de conexión o vinculaciones entre la Carta Social y la cláusula social.

La Carta Social puede operar como una cláusula social si su incumplimiento acarrea sanciones propias del comercio intemacional. De lo contrario, no; y continuarán siendo diferentes. A su vez, la cláusula social puede remitir a una Carta Social: un convenio comercial puede contener una cláusula (social) que establezca sanciones o la rescisión en caso de no respetarse derechos sociales contenidos en una Carta Social o en un convenio internacional del trabajo o en cualquier otro instrumento autónomo. Es más, toda cláusula social necesita identificar cuál o cuáles son los derechos cuya violación opera la rescisión del acuerdo comercial o suspende los beneficios comerciales acordados 0 autoriza la aplicación de multas. Esos derechos pueden ser definidos en la misma cláusula o en una enumeración anexa o remitirse a un instrumento independiente (que puede ser una Carta Social o una Declaración o un convenio internacional del trabajo, etc.).

Por otra parte, la cláusula social también puede remitir (no a derechos por ella definidos, ni a derechos contenidos en otro instru- mento, sino) al control del cumplimiento acordado de toda o parte de las legislaciones nacionales. Este puede ser un mecanismo diferente a la Carta Social y a la cláusula social, pero también puede ser visto como una modalidad de cualquiera de ellas.

La posibilidad de condicionar el comercio internacional al cumplimiento de derechos laborales a través de las cláusulas sociales, ha dado lugar a un intenso debate. No es este el momento de entrar en el mismo, lo que exigiría un ensayo específico dedicado exclusivamente a esta cuestión. Basta señalar aquí la inevitabilidad de la cláusula social o de mecanismos alternativos. Si no se logra la aplicación y el cumplimiento efectivo de los convenios internacionales del trabajo, Declaraciones, Pactos y Cartas Sociales, ciertos países se verán inclinados a imponer cláusulas sociales en sus acuerdos de comercio o a aplicar medidas unilaterales con la finalidad o el pretexto de promover el cumplimiento de aquéllos y de evitar el "dumping social", lo que ya ha comenzado a suceder.

6.6 Entre los sistemas unilaterales sustitutivos de las cláusulas sociales, los hay nacionales, regionales y privados-voluntarios.

El Sistema General de Preferencias arancelarias de los Estados Unidos de Norteamérica ilustra el primer tipo. Entre las condiciones que el gobiemo estadounidense impone unilateralmente para hacer efectivas las ventajas arancelarias reconocidas a los países subdesarrollados, se incluye la de que el pais en cuestión tome o haya tomado disposiciones para conceder a sus trabajadores los derechos que se les reconocen en el plano internacional.

La "cláusula laboral" prevista en el Reglamento C.E. No. $1154 / 98$ de 25 de mayo de 1998, de la Unión Europea, ejemplifica el segundo tipo: una medida sustitutiva de la cláusula social, impuesta unilateralmente no ya por un Estado, sino por un bloque regional. En él se estipulan reducciones arancelarias de entre el $10 \%$ y el $35 \%$ a favor de productos industriales provenientes de países en vias de desarro- 
Ho cuya legislación y práctica apliquen los principios contenidos en los convenios internacionales del trabajo Nos. 87,98 y 138 , sobre libertad sindical, negociación colectiva y edad mínima de admisión al empleo.

Los códigos de conducta, los "labels", sellos o distintivos de buena práctica laboral y las iniciativas de "inversiones socialmente responsables", son todos iniciativas privadas, voluntarias $\mathrm{y}$ unilaterales de empresas 0 grupos de empresas que tienden a promover $y$ difundir el cumplimiento de ciertos mínimos laborales. Sin embargo, su unilateralidad y voluntariedad limitan su eficacia y afectan su credibilidad casi tanto como las dudas acerca de su verdadero objetivo: $\iota$ respeto de derechos sociales o mera publicidad $y$ campaña de imagen? 